\title{
Integrating 3D Scanning Data \& Textile Parameters into Virtual Clothing
}

\author{
E. Jess POWER*, Phoebe R. APEAGYEI, Aileen, M. JEFFERSON, \\ Manchester Metropolitan University, UK
}

\begin{abstract}
Globalisation has changed the face of the clothing and textile industries in many developed and developing nations. In the twenty first century no longer are clothes manufactured and retailed in specific local regions. Fashion and clothing have joined textiles in becoming a truly global operation. Despite this revolution many authors report that clothing and textiles still lag behind other manufacturing industries in relation to their enthusiasm to adopt new product development processes. The traditional clothing product development route is labour and time intensive and this process often involves a series of fit trials on live models to ensure satisfactory fit is achieved.
\end{abstract}

Garment design and realisation is a highly specialised domain which demands skills across a wide variety of disciplines. CAD and computation technologies in apparel have existed for a number of years however they have provided separate working environments for those involved in design and garment construction. Whilst each specific system has been successfully integrated into their respective stage of the product design process, they have created a distinctive divide between design and apparel construction. Virtual simulation software could reduce or completely eliminate the intensive sampling stages by providing a true to life representation of the product without embarking in any physical manufacturing. It offers the opportunity to design, produce patterns, create a virtual manufactured garment and test fit in one environment.

Many authors have identified essential components within 3D virtual simulation as; the digital cloning of the human body, the exact input of fabric parameters, precise computation models, and effective joining of the 2D pattern components. Modelling a human form (avatar) and simulating tactile materials involves collaboration across many different disciplines. The human body is a complex form and virtual representation is dependent on accurate physical anatomical landmarking. Modern 3D body scanning has provided the opportunity to obtain sophisticated data in relation to a 3D form. 3D scans generate thousands of data points which can be manipulated to create static or dynamic forms. The animation industry has utilised this technology extensively in gaming during the last century, which has generated much interest within the apparel industries.

Virtual garment simulation offers opportunities in apparel in four distinct areas; Firstly speed to market; Secondly, opportunities for niche and luxury custom made garments where the customer could be the designer of their own garment; Thirdly, in e-commerce, a garment could be selected from a multimedia catalogue and viewed on a body shape similar to the consumer; and finally in the development of fitted garments (sportswear and intimate apparel) where the apparel could be designed with accurate mapping of comfort and support. 3D virtual simulation is set to play an important role within apparel product development in the future. This paper presents a discussion regarding 3D scanning technologies, available 3D virtual simulation software and methods of obtaining the fabric parameters. One commercial system is discussed in terms of the integration between the body scanning data and the resultant avatar, and the inputting of the textile parameters in relation to the fabric representation.

Keywords: Virtual garment simulation, 3D body scanning, virtual modelling of textiles

* Corresponding Author

Dr. E. J. Power j.power@mmu.ac.uk +44(0)161 2472676

Department of Clothing Design and Technology

Hollings Faculty

Manchester Metropolitan University

Old Hall Lane,

Manchester M14 6HR

UK 


\section{The global clothing and textile industry}

During the latter quarter of the $20^{\text {th }}$ century the clothing and textile industries of many developed and developing nations have changed dramatically. The industry is highly complex, with some of the longest and most complicated pipelines of the manufacturing sector $[1,2,3,4,5,6]$. No longer are clothes manufactured and retailed in specific local regions. Fashion and clothing have joined textiles in becoming a truly global operation with many manufacturing functions blurring $[3,5,7,8]$. A garment purchased in the UK is likely to contain components manufactured in Europe, or elsewhere in the world. It is highly probable that the textile material has already travelled between various locations prior to garment construction, which is likely to occur in a low cost labour countries such as Cambodia, China or perhaps Bangladesh.

The driving forces of this shift is the advances in technology [4,9]. Recent innovations have made it possible to trade on a global basis, competition of a global nature has transformed the supply chain $[4,9]$. Technology has affected every market sector including the manufacturing industries. In a globalised environment there is high competition as well as significant opportunities in which the apparel industries need to be prepared for. In recent years the developed world has changed the way it engages with textiles and clothing. Companies are opting to keep their headquarters, design, marketing and in some cases prototype and test facilities onshore. This facilitates innovation in materials, fabrics and production methods since they have the financial resources to visit and source from international yarn and textile trend shows and view the latest developments in machinery and manufacturing. Today, textile and clothing is accredited to be one of the most globalised industries worldwide, worth $£ 500$ billion, and it provides employment for over 26 million individuals within the sector [6].

\section{Product development process}

The product development process begins with the design concept and ends when the garment is released for production. The traditional clothing product development route is labour and time intensive. It involves all aspects of research into market and trend direction, including colour, style and fabric. Ideas are developed into preliminary sketches which lead to range developments. Once the range is finalised, the process of preparing the components to enable each individual garment to be manufactured is undertaken. Technical specifications are created from the original designs leading to pattern development, this is followed by the manufacture of a prototype sample which will be approved for fit and style using a live model. If any adjustments to the prototype garment are required appropriate modifications will occur and the technical specification and pattern adjusted accordingly. This often results in a lengthy process, as more than one prototype sample may be produced for each style. Once the range is finalised each garment will be graded into the appropriate sizes and released for production.

Satisfying the demands of the customer, who want fashionable garments of a high quality at affordable prices is becoming increasingly challenging $[10,11]$. Therefore, ways to reduce time to market are constantly being reviewed. It is reported that the product development time can be as high as $70 \%$ in a typical garment life cycle, whilst the actual manufacture only corresponds to $30 \%$ [12]. Speed to market is crucial in a rapid response environment and the reduction of time in the developmental stages is essential. In an attempt to facilitate the traditional process CAD software packages have been introduced into garment development; CAD packages are used by fashion designers to illustrate the seasons ranges, 2D pattern design (PDS), grading and marker-making packages are used extensively in the manufacturing industry, and product lifecycle management (PLM) software is utilised to manage data and aid communication across the global supply chain.

\section{Technology integration}

During the last decade technology has advanced at an astronomical speed [13]. A major force driving the technology is the competitive retail environment. The fast fashion phenomena has forced retailers to react quickly to trends and significantly improve response times $[10,14,15,16,17]$. It has been reported that fast fashion turns sketches into products in a matter of weeks $[11,18]$. Utilising technology to reduce product development time would have significant impact on the product development process. In other manufacturing and construction industries (car manufacture, architecture) technology, in particular CAD appears to have become the accepted norm to facilitate product development. However, it is reported that the apparel sector as a whole is lagging behind in its willingness to adopt new processes to aid product develop process, despite there being many new innovative products on the market [7]. 
One underused technology is 3D virtual simulation, although this has been in existence for a number of years, various authors have acknowledged its lack of practical application and adoption within the clothing industry $[19,20,21,22,23]$. This is accredited to a variety of reasons including, setup costs, user expertise, technology limitations and accurate fabric simulation. However, during the last few years significant developments have occurred to make the software more user-friendly and intergratable with other systems and technologies currently on the market. There are opportunities within niche garment production, sportswear, e-commerce and mass production which can exploit the virtual clothing phenomena. Whilst the transition from 2D to 3D design occurred over 15 years ago in other manufacturing industries, modelling garments appeared to be inhibited by two factors, the accurate computer representation of the human form, and the realistic simulation of material drape $[19,24]$.

\subsection{Virtual software}

Research into virtual garments began to gain momentum during the 1980s, when the film industry became interested in 3D computer generated images [25]. In the graphic visualisation of textile materials physical accuracy was less important than the aesthetic representation. However, the gaming industry can be accredited to accelerating the speed of research into visual cloth simulation. Of course further research was required into the modelling of the textiles physical parameters before the technology could be utilised within the garment development industry. Fabric simulation required mechanical models that replicate the properties of the cloth, and whilst studies date back to 1930 there have been significant challenges in modelling textiles due to the vast range of fabrics used in clothing and the sophistication of the computer themselves. Recent advances in computational power and hardware performance has enabled the development of 3D CAD systems that are aimed at the fashion and clothing industries [26,27]. Hardaker and Fozzard acknowledged that 3D CAD systems are now being seen as a garment visualisation and a pattern making tool [23].

Two approaches emerged regarding the development of virtual garment simulation software. The first was designing in the 3D form and flattening the 3D images created on a virtual model to produce $2 \mathrm{D}$ patterns. In the early 1990s a US based company Computer Design Inc. offered this function within its garment design software [26]. However, there were commercial limitations to this software, one of which was the necessary for the garment to be in proximity to the body and the second was the designers technical ability. This approach to 3D design has found a niche in the automotive industries with companies such as Lectra offering DesignConcept Auto 3D. The second approach, which is more common commercially in the garment industry, is the $2 \mathrm{D}$ to $3 \mathrm{D}$ method. $2 \mathrm{D}$ patterns are assembled in a 3D environment on a virtual model; the virtual garment can be viewed from any zoom level and rotated a full $360^{\circ}$. Although the $3 \mathrm{D}$ to $2 \mathrm{D}$ route presents a favourable solution, $2 \mathrm{D}$ to $3 \mathrm{D}$ is more aligned with the current garment product development process. Commercial systems on the market include Lecra's Modaris 3D fit, Browzwear's Vstitcher, PAD's Haute Couture 3D, Optitex's 3D runway designer, Human solutions and Assyst-Buller's Vidya (part of Human Solutions).

\section{Garment Fit}

In the clothing and textile industry, the search for perfect clothing fit has a long history relating to various efforts to determine body anthropometry for the creation of patterns, development of garments; and for satisfactory textile and fabric drape on the human body $[28,29,30,31]$. Anthropometrics (the science of human measurement and classification of the human body based on size and shape) is precedent to accurate clothing fit and therefore fundamental to production, retail and consumption. With advancement in technology, automated non-contact 3D body scanners designed to capture the shape and size of a human body in seconds and further produce its true-toscale 3D body model have been developed $[40,41,42,43,44,45]$. These deliver speed, objectivity, validity and reliability and therefore an essential tool for education, research and development.

The use of data generated by the 3D body scanner is extensive and includes morphology for the creation of avatars and mannequins. This technology is currently viewed as the frontier in solving fit problems, for instance by enabling a pragmatic approach to the offer of mass customisation and facilitating virtual fit testing that stand to enhance online clothing shopping experiences [32]. Consumers have become savvier than ever and as the demand for well-fitted garments is increasing, 3D body scanning technology is being viewed as a significant bridge between craftsmanship and computer-aided design and manufacturing (CAD/CAM) technologies. It is currently being explored by academic research and is not as yet being widely implemented across the retail sectors. However, it 
is expected to; facilitate best fit for intimate apparel and performance wear, enhanced physiological clothing comfort, improved consumer satisfaction and subsequently reduce commercial waste due to 'ill-fit' returns.

\subsection{Importance of accurate body measurements}

The shapes of human figures continue to change with time, mainly due to sedentary lifestyles, dietary habits, migration patterns and the impact of rising trends [33,34,35,36,37]. Although this necessitates regular monitoring and application of accurate, up to date body measurements in the clothing and textile industry, such research can nonetheless be time consuming and costly. As well as being considered proprietary, precise, detailed information on anthropometric output data has not been easily accessible in the public domain. Prior to UK's national sizing survey in 2001-2002 in which 3D body scanners were first employed, body measurement data dating as far back as 1951 were being used in pattern development and sizing for clothing. Results of this survey [38] showed that there has been a significant change in human body size generally within both genders.

Utilisation of current and efficient individual or clustered anthropometric data is significant to the provision of adequate clothing. Body scanning technology has significant advantages over traditional manual body measurement procedures: it is quick, efficient, non-contact and generates efficient data for size charts, pattern generation and fit testing for clothing. Many eliminate the likelihood of invalid, unreliable and subjective measurement procedures; and vague judgements of posture. The extensive measurements and body models provide a foundation for specified batch and individual pattern construction based on accurate body measurements, thereby eliminating observer error inherent in traditional methods [39]. In general, the uses of body models generated by 3D body scanning seem unlimited. These include: 3D shape data for avatar creation for online shopping, virtual fit trials, 3D product development, body dimension analysis for target markets, animation and graphics, health and fitness management [43]. For mass customisation, the measurement procedure could be carried out only once but allow future re-use of stored data for new garment orders for instance; thereby enhancing opportunities for consumer loyalty in retail business terms.

\subsection{Methods of obtaining body measurement data}

Obtaining body measurement data commences with specific procedures and infrastructure based on the selected method. With traditional, manual methods precise location of body landmarks and how these are handled can be subjective, due to the awkward positioning of certain measurement areas (for example, crotch for inside leg measurement), and there are also issues regarding ethical considerations. 3D body scanning is similarly not without challenges related to landmarking [39]. Furthermore, some scanners require subjects to wear undergarments during the scan. Currently, capturing a 'good' scan in a posture that allows extracting specific measurement varies among systems.

The development of 3D body scanning technology allows for the quick and consistent extraction of body measurements and can generate customised fit for any number of people. As well as linear measurements, scanning extracts a vast number of data types and measurements relating to shapes, angles, and relational data points $[28,40]$. They capture accurate 3D representation of a garment's relationship to the body while minimising visual distraction [41]. The extracted measurements and the body model output are the foundation for virtual clothing. The 3D image (body model) allows instant evaluation regarding validity of the scan; and the dimensions and shape data could be used repeatedly for various garments without the need for repeated measurement. The measurements obtained using this technology is more precise and reproducible than those obtained through the traditional, physical measurement process.

\subsection{Scanning technology overview}

The 3D scanning technologies used for body measurement extraction on today's market are based on various systems. These may be driven by laser, structured or white light technology and are able to scan millions of measurement data points in seconds. The scanning process captures an array of digitized points represented by $x, y$, and $z$ coordinates for shape. The laser scanners work on the basis of a light-plane and triangulation method. Laser is used as a light source and a couple charged device (CCD) scans the field of view and detects the displacement of the light on a body [42]. Structured or white light scanners project a series of white-light stripes onto the subject for data capture via cameras $[43,44,45]$. The 3D shape of the body is described through the curve of the stripes over the subject. Studies have shown that during the scanning sequence light projection 
systems are faster than laser based systems. But for measurement extraction, these types of scanners are slightly slower [46]. The latest scanning technology to become a commercial reality uses radio wave technology, Intellifit, virtual fitting room body scanner allows body data to be captured in 20 seconds whilst the participant is fully clothed. Although there are variability and incomparability of measurements between the various technologies available [28,39], their common aim is to scientifically extract anthropometric data in a valid and reliable manner. 3D rendering tools allow the viewing of 3D scan data immediately on completion of the scan, which can be saved in multiple output formats.

In business terms, body scanning is helping to shift the focus of apparel production from mass production to mass customisation with individualised sizing and design features. For functional and performance wear, it provides solutions to fit precision on various body types that promote physiological well-being and enhance performance. Integrated software is crucial to the process of linking scan data to CAD patterns. Therefore, compatibility between systems needs to be ensured for the process of automatic generation and manipulation of garment patterns and also for fit trials. Systems are usually web enabled and allow direct data transfer from the scanner over local networks or over the web into the existing CAD applications. Body scanning systems now claim to be able to integrate scan data into current, available apparel CAD systems. Many capture and produce an open format for $\mathrm{x}, \mathrm{y}, \mathrm{z}$ coordinates data and store that as ASCII file, while others have a proprietary file format complemented by an open exchange format. Exporting 3D data for garment pattern modification and draping simulation is made possible [43,47].

\section{Textile properties}

Textiles used in clothing vary from highly rigid materials used to provide support and protection, to flexible structures with high elasticity where comfort is paramount. They find applications in fashion garments, sport attire through to performance clothing. Although the term "textile" was originally used to describe a fabric of woven manufacture, the term textiles are now universally applied to products where fibres, yarns and fabrics form the principal raw material [48]. For the purpose of this paper a textile will be defined as a tactile material produced from fibre, yarn or fabric for the use in clothing. It is the tactile nature of textile materials that provides significant challenges in virtual modelling, since each combination of fibre, yarn and fabric provides a unique set of properties. The basic components and their arrangement significantly influence the behaviour and appearance of the final textile. It is the extensive spectrum of textiles suitable for clothing applications that makes virtual modelling a highly complex discipline. Textile materials vary in weight, thickness, texture, flexibility and handle, and all of these factors must be considered if a realistic simulation is to occur.

One essential requirement of a textile material intended to be used for a clothing application is comfort in the aesthetic and physiological sense. Textiles materials have been evaluated for many years using sensory techniques. Fabric hand or handle can be evaluated by simply by touching the material, this is termed subjective assessment. The sensory experience is produced when the fingers make contact with a material. However, this is a complex parameter to simulate since properties such as softness, stiffness, roughness, flexibility and temperature are often difficult to quantify in numerical terms. In contrast objective assessment attempts to quantify fabric hand through measuring the textile material properties objectively.

\subsection{Objective fabric measurements}

Textile materials are usually defined in terms of aesthetics, mechanical and physical properties. In 1930 Peirce devised physical tests that analysed and reflected the sensation experienced in fabric hand. Since then many studies have been undertaken and important functional properties such as; surface contour, density, surface friction, flexibility, compressibility, elasticity, resilience and thermal attributes have been identified as important in quantifying fabric handle $[49,50,51,52]$. Despite many studies to identify relationships, the first key developments in the standardisation of textile objective handle were made by the Japanese with the development of the KES-F (Kawabata evaluation system). This system provided precise predictions of fabric handle and was credited to provide the answer to the relationship between the functional (mechanical and physical) properties of textiles and handle [20]. The calculated standard fabric hand values are not of particular interest for virtual simulation but the actual measured data is extremely important. The KES-F system is very sophisticated but required significant expertise to use and analyse the results, which along with its hefty price tag limited its use in commercial markets. 
FAST (fabric assurance by simple testing) was developed in the late 80 s by CSIRO (Commonwealth Scientific Division Research Organisation) as a simpler alternative to the previously described KES-F system. The system was designed for use in the tailoring and wool/worsted finishing industry [53]. The system consisted of 4 pieces of apparatus to measure the textile properties of fabric thickness, bend, extension and dimensional stability. The main advantages of this objective textile testing system was its low cost (if compared to the KES-F), ease to use (with no prior knowledge) and once the textiles were conditioned the tests can be completed in less than 1 hour $[20,21,54,55]$. The KES-F and FAST systems measure similar fabric parameters but the principles used vary enormously. Various authors critique the two systems and many comparative studies have been completed $[20,21,54,55,56]$. Despite the provision for objective measurement being dominated by the above two systems other more cost effective systems are being developed with a focus on reducing the time and skill level taken to obtain the required parameters.

To enable virtual garment simulation to occur two factors are paramount; firstly the accurate representation of the human form, and secondly the realistic cloth simulation. Volino and MagnenatThalmann identify five individual components that are required for accurate cloth simulation; material analysis, mechanical modelling, geometrical modelling, simulation scheme and numerical integration [57]. Virtual garment simulation involves the integration of many different disciplines including, textiles, physics, mathematics, electronics and computer science [58]. Communication is vital within the traditional garment product development processes, and extensive research has been done to explore the communication between the various parameters required for virtual simulation [19,57]. All virtual garment simulation software requires the inputting of objective fabric measurements. Some companies have developed simpler testing solutions regarding methods to obtain the required textile parameters, but most software provides an option to utilise the data obtained from FAST test system. Generally the textile parameters required for virtual garment simulation are; bend, elongation, shear, mass and fabric thickness.

\section{Virtual inputting of parameters}

The developments in 3D garment virtual simulation have been significant over the recent years, and many products exist from a variety of suppliers. This paper discusses the Vstitcher (by Browzwear) software in detail. Browzwear is an Israeli company established in 1999 which specialised in providing 3D solutions to both retail and production environments. In 2001 Vstitcher (its first commercial application) was presented [19]. The software enabled 2D patterns to be simulated in 3D on a realistic human form. Since 2001 the technology has evolved to become one of the leading names for 3D solutions for apparel on the market. In 2005 Vstitcher partnered with Gerber Technology an international leader in the development of software and hardware solutions for the apparel industry. Vstitcher is marketed to be one of 'the most powerful 3D design and visualisation software' available today [47]. It interfaces seamlessly with Gerber's Accumark pattern preparation system, 'enabling a fast and easy transformation of 2D patterns into 3D garments' [47]. Its manufacturers claim it 'significantly reduces product development costs and improves time to market through the creation of virtual samples' [47], which are key factors in a competitive retail environment.

The process of creating a 3D virtual garment simulation begins with a 2D pattern; pattern pieces are imported into Vstitcher from Gerber's Accumark software. In the Vstitcher environment all pattern seam allowances should be removed, this is best achieved in the 2D pattern preparation software. The individual pattern pieces can be moved around and rotated for ease of view within Vstitcher (Figure 1a). An important step in the 3D process is to create a GMap (a garment map or specification) this holds all the style data and enables a garment identification number to be created. To enable the 3D simulation to occur the pattern pieces need to be arranged in clusters, one cluster would contain all the components of the sleeve, another would be created for the front body and so forth (Figure 1b). Following on from this process the stitching areas need to be defined (which parts of the garment panels join together) Figure 1c illustrates this process. The correct fabric should be assigned to each component of the garment (Figure 1d). The fabric visual representation can be created through scanning in the actual textile material and the material properties can be inputted as discussed in section 6.2. The Vstitcher software enables textures to be layered over each other to create motifs, seam detail, washed and faded effects should the garment designer desire these effects. At any stage in the process an avatar can be selected from the vast range available within the internal library. The avatar can be customised (morphed) by the user in terms of dimensions and shape characteristics; this process is discussed in section 6.1. To facilitate the dressing of the avatar the position of the pattern pieces must be defined. Once the pattern pieces are correctly positioned the virtual simulation 
process begins (Figure 1e). The completed 3D simulation can be viewed from a variety of angles and can be rotated $360^{\circ}$. To enable the fit to be assessed, tension and pressure maps can be applied. These are displayed using a coloured scale to highlight the severity of the force applied to the avatar (tension map illustrated in Figure 1f).

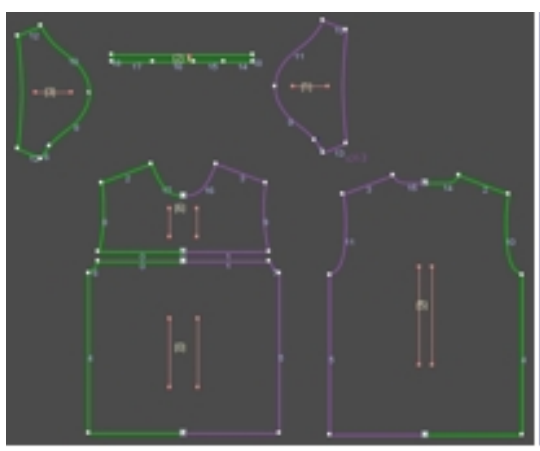

$1 \mathrm{a}$

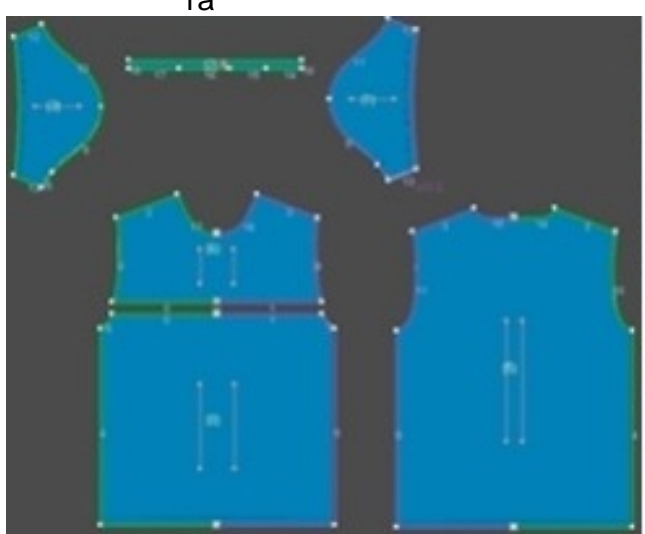

$1 d$

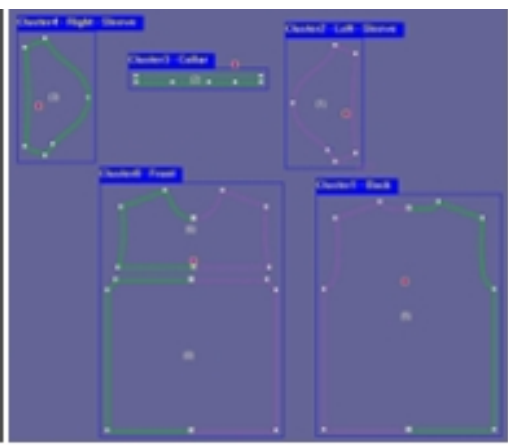

$1 b$

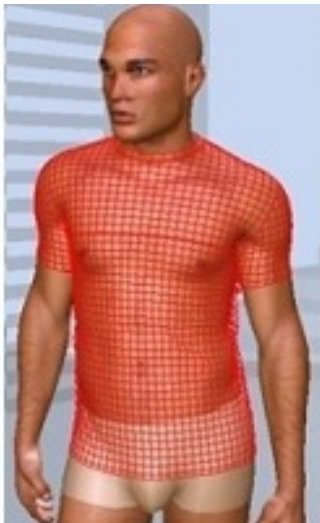

$1 \mathrm{e}$

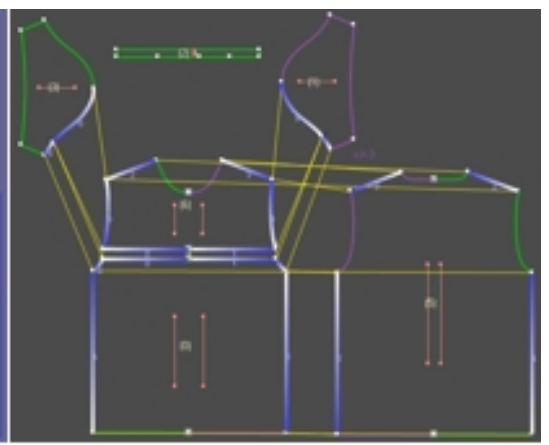

$1 \mathrm{C}$

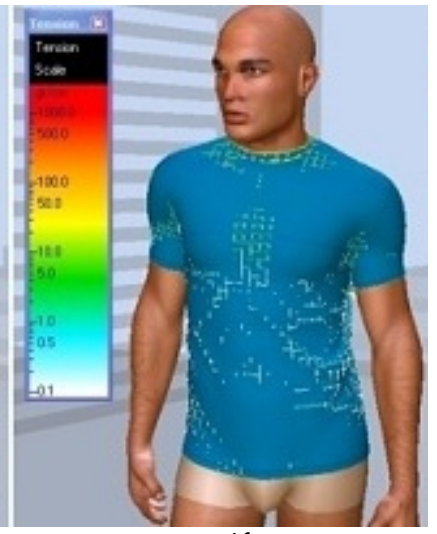

1f

Fig.1. Process of 3D virtual simulation (Vstitcher V4.4, 2010)

\subsection{Interpretation of body scan data}

Data from body scanning can be used for diverse needs in the clothing industry including made-tomeasure, customisation, fit trials, developing standardised size for specific targets, creating niches, efficient communication during manufacturing processes, efficient and rapid prototyping and online shopping. Istook and Hwang validate that to obtain accurate physical measurements, a basic knowledge and specific know-how skills are required [46]. Moreover beyond measurement acquisition analysis of data is determined by the objectives of the measurement. Body scanners generate comprehensive sets of measurement. These communicate the list of measurements, measurement points, body segments, joints and landmark splicing, volume and even extra measurements offset from standard landmarks. They further permit saving of data in various file formats and some interface with other existing CAD applications. Scanning systems allow rotation of scanned images and various angles of the scanned data to be examined. It is possible to present body measurements for individuals, small and large batches. $[T C]^{2}$ 's scan data output allows the extensive list of measurements to be customised, thereby allowing specific profiles required for selected garment types and standardised size tables to be automatically produced. Nearly 200 left and right body measurements can be automatically extracted within 8-10 seconds for individual full scans [Figure 2a]. Optional 3D avatars and garment draping simulation can be instantly automatically generated using integrated software Image Twin ${ }^{\mathrm{TM}}$ [Figure 2b] and other interfaces such as OpiTex which allow animation. An alternative method using the Vstitcher software requires physical data input of body measurements relating to height, body silhouette, torso, legs, hands, body shaping, face and expression. Measurement data from the scanner may be combined where applicable (eg. left and right body parts), since the avatar generated is symmetrical, unlike the data obtained from the scan. In most cases, the selection for data input is made from menu options. 


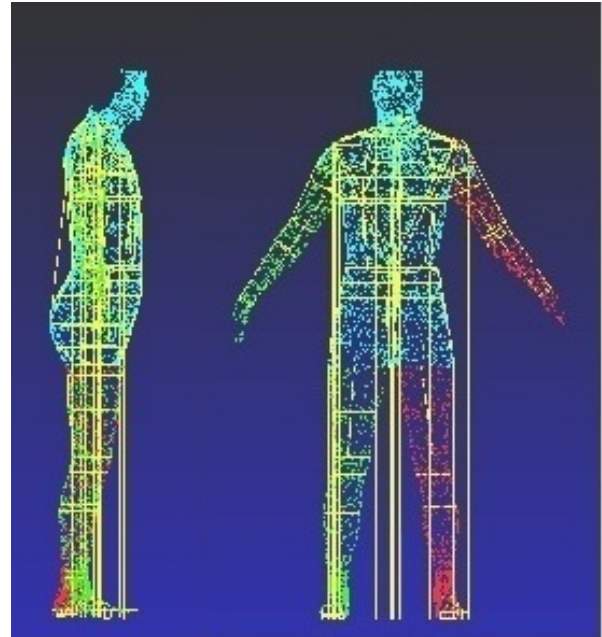

$2 \mathrm{a}-3 \mathrm{D}$ body measurement data output

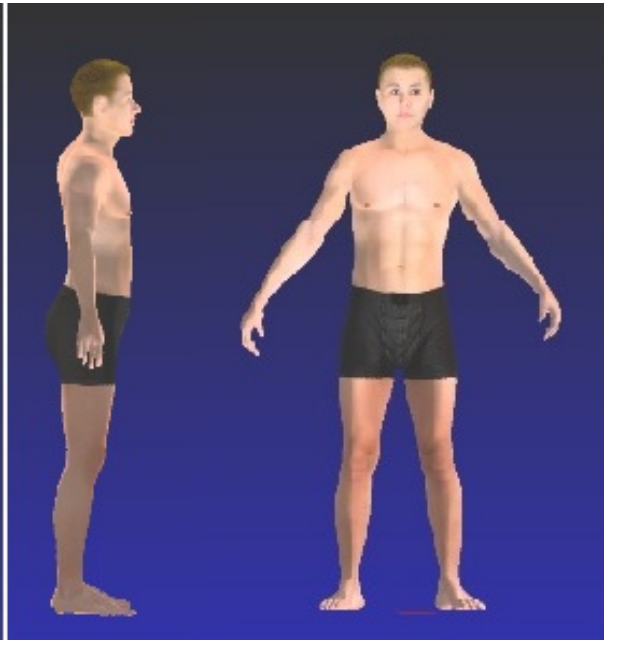

$2 \mathrm{~b}$ - Corresponding image avatar

Fig. 2. 3D Scan Data output (TC ${ }^{2}$ and Image Twin, 2011)

\subsection{Interpretation of textile parameters}

The Vstitcher software enables the specific textile properties to be inputted directly if the objective parameters are obtained directly from Browzwear's own fabric test kit. In the latest versions the standard physical units of mass, bend and stretch are used to simulate drape, although new textile parameters of thickness and hysteresis are incorporated in the fabric simulation within the latest versions. There is the option to input a value for shrinkage but this is not currently utilised for simulation. Alternatively results obtained using the FAST system can be converted into the properties required for Vstitcher via a separate conversion utility.

Fabric stiffness is an important parameter in virtual simulation and is expressed as bend. The Browzwear fabric test kit measures the bending length of a material under its own mass. Bend is defined to be the materials resistance to bending under a given force. It is beyond question that the mass of a fabric will influence drape significantly and therefore when the bend property is calculated in the Vstitcher software, the mass of the fabric is a required parameter. Bend is expressed in dyne/cm. The most significant force in the Vstitcher's simulation is stretch [59]. The property of stretch represents the correlation of elongation at a given force in the warp, weft and bias directions. The Browzwear fabric test kit offers a simplistic approach using a stain gauge principle. The fabric is mounted so it is free hanging, a series of weights are applied and the user records the fabric elongation. The values are inputted directly into the stretch test calculator, and the stretch and shear parameters are automatically calculated (high values indicate a fabric with low stretch). The results are expressed in $\mathrm{N} / \mathrm{m}$ for both stretch and shear.

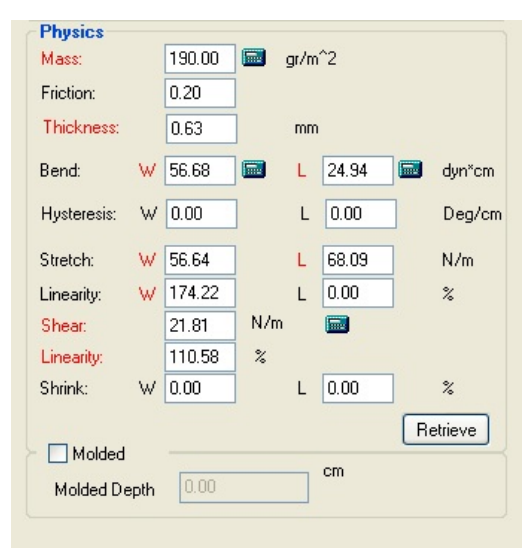

Fabric One's Properties

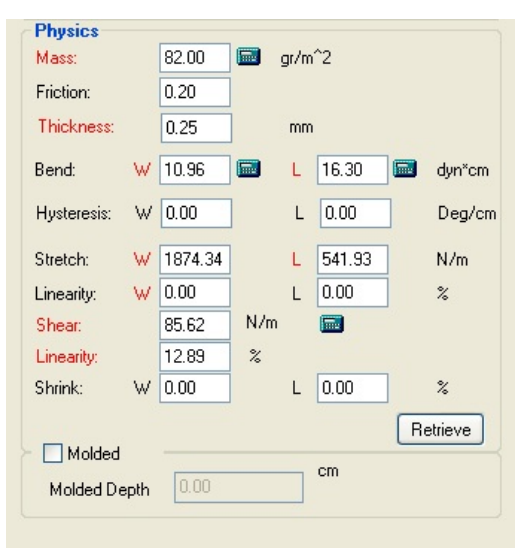

Fabric Two's Properties

Fig. 3. Calculated Fabric Properties (Vstitcher V4.4, 2010) 
Figure 3 displays the derived properties for two selected textile materials used within the virtual simulation. Fabric One is a weft plain knitted structure ( $87 \%$ polyester / $13 \%$ Spandex) with a mass of $190 \mathrm{~g} / \mathrm{m}^{2}$ and Fabric Two is a $100 \%$ polyester microfibre woven structure with a mass of $82 \mathrm{~g} / \mathrm{m}^{2}$.

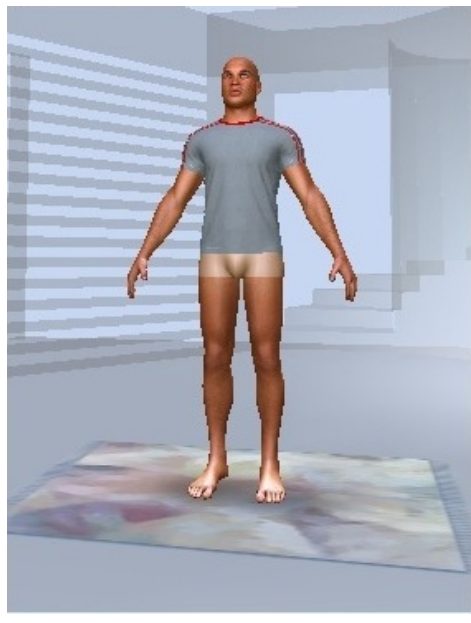

Virtual Simulation Using Fabric One Properties

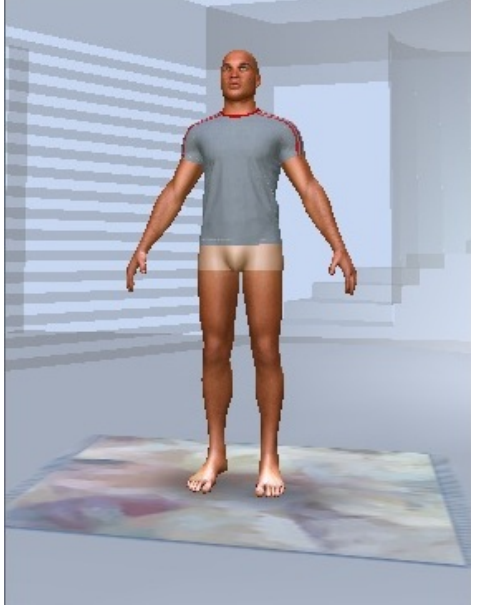

Virtual Simulation Using Fabric Two Properties Fig. 4. Resultant simulation (Vstitcher V4.4, 2010)

Using a basic T-shirt from the Vstitcher library the garments were simulated using the different textile properties. The resultant simulations are displayed in Figure 4 - it can be seen from the virtual representation that although the fabric properties are vastly different the simulation appears to be very similar. However, if a pressure map function is applied to the avatar, the effects of the different textile material properties in relation to the human form can be seen clearly (Figure 5). The woven structure (Fabric Two) demonstrates area of high pressure (yellow and green); whilst the knitted structure (Fabric One) demonstrates areas of significantly lower pressure around the arm, shoulder and waist areas (green, blue, white).

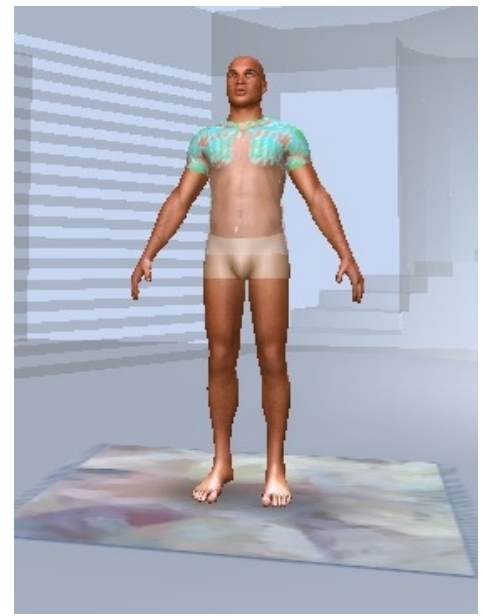

Pressure Simulation Using Fabric One Properties

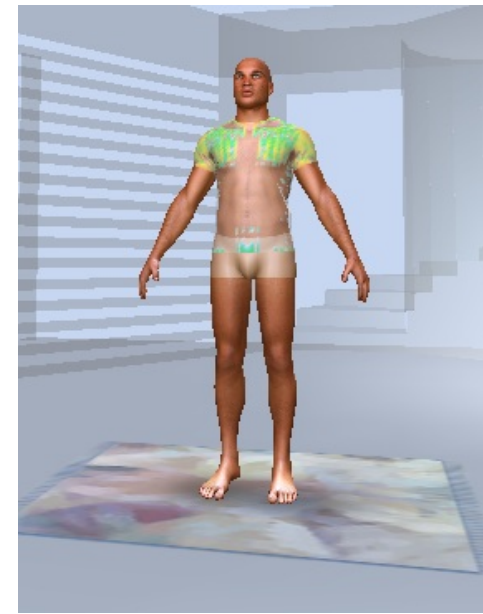

Pressure Simulation Using Fabric Two Properties

Fig. 5. Pressure simulation (Vstitcher V4.4, 2010)

The above trial highlights the difficulty of assessing garment fit through virtual simulation. Fabrics with vastly different properties may appear to have a very similar appearance when modelled virtually (Figure 4). However, in reality a woven fabric would be highly unsuitable for the garment style demonstrated in the trial, and could result in discomfort during wear (Figure 5). It is clear when assessing fit in the pressure map mode that there are significant differences between the two selected 
fabrics properties. The woven fabric (Fabric Two) is clearly displaying higher pressure being applied to the body (yellow and green) this is a due to the high stretch resistance within the woven material. The high pressure demonstrated in wear would indicate that the material is highly unsuitable for this particular styleline.

\section{Summary}

This paper clearly illustrates that the clothing and fashion industries are highly complex and volatile with some of the longest pipelines of any manufacturing sector. In the last decade or so the developed and developing nations have changed the way they engage with textiles and clothing. Through literature it is ascertained that the driving force behind this shift is the advances in technology. Innovations in technology have made it possible to trade on a global basis which has transformed the traditional garment supply chain. Driven by consumer demand, the fast fashion phenomena has forced retailers to react quickly to trends and this has resulted in a demand for improved response times within the supply chain. The traditional clothing product development route is labour and time intensive often resulting in more than one prototype sample being produced for each style. It is reported that the product development time can be as high as $70 \%$ in a typical garment life cycle, whilst the actual manufacture only corresponds to $30 \%$. Utilising technology to reduce product development time would have significant impact on the time to market. In other manufacturing industries CAD appears to have become the accepted norm with the transition from 2D to 3D design occurring over 15 years ago. However, modelling garments appeared to be inhibited by two factors, the accurate computer representation of the human form, and the realistic simulation of material drape.

In the last decade there have been significant advances in computational power and hardware performance which has enabled the progression of 3D CAD systems which are specifically aimed at the clothing industry. Although numerous researchers are investigating and developing 3D CAD systems from the 3D to $2 \mathrm{D}$ concept, the emerging commercial companies are favouring the $2 \mathrm{D}$ to $3 \mathrm{D}$ approach as it mirrors the current product development process which development personnel are familiar with. This paper details the process of creating a 3D virtual simulation in the Vstitcher software. The process began with 2D pattern pieces being imported and ended with the 3D garment simulation which can be viewed from a variety of angles. The Vstitcher software enables the specific textile properties and body measurement data to be inputted directly. This makes it possible to simulate a vast array of textile structures and generate a true to life representation of the human form (avatar).

3D body scanning technology contributes to theory and better understanding of factors regarding human body measurement and categorisation. Their reliability, precision and speed continue to optimise activities relating to acquisition and digitisation of body measurements data, and virtual garment simulation. However, precise generation of body models derived from 3D body scanning only form a part of the process in adequately assessing fit within the virtual clothing environment. It is evident that there are still significant challenges in the virtual modelling of textile materials. Two textiles were selected which exhibited vastly different properties. The objective parameters were obtained and inputted into the Vstitcher's virtual simulation software. The resultant simulations looked identical despite the fabric properties being vastly different. However, if the pressure applied to the body as a result of the garment is examined the effects of the different textile material is clearly visible. This highlights the difficulty of assessing garment fit through virtual simulation. Fabrics with vastly different properties may appear to have very similar drape, when in reality they may not be suitable for the application. This demonstrates that there is still further work to be undertaken in the precise modelling the human form and true to life fabric simulation.

3D virtual simulation has made significant progress in the last decade and is the current innovation expected to be widely implemented in commercial product development processes. In today's globalised, competitive environment, there are significant opportunities for engagement with this technology and integrated systems. It has been predicted [60] that clothing companies will continue to go through tremendous changes to create environments where consumer requirements are not only met but exceeded; and where efficiency, productivity, quality, customer satisfaction and competitiveness are critically considered as success factors. Currently, the increasing turbulence of the global market has altered the nature of the clothing and textile industry. Conventional competitive advantages are no longer sustainable and at present the integration of 3D body scanning technology 
and virtual garment simulation are viewed as the cutting edge for adequate provision within the industry. Although the potential seems remarkable, the cost and real benefits will become more apparent with time.

\section{References}

1. Bruce, M., Daly, L., Towers, N., (2004): "Lean or agile? A solution for supply chain management in the textiles and clothing industry?", International Journal of Operations \& Production Management, Vol.24, No.2, pp.151-170.

2. Jack, S., (2007): “'Keeping up with fashion”, Motor Transport, 7/12/2007, pp.36-38.

3. Jones, R. M., (2006): "The apparel industry", Blackwell Publishing Ltd, Oxford.

4. Kunz, G. I., Garner, M. B. (2006) "Going global: The textile and apparel Industry", Fairchild Publications Inc, New York.

5. Soni, G. and Kodali, R., (2010): "International benchmarking for assessment of supply chain performance", Benchmarking: An International Journal, Vol.17, No.1, pp.44-76.

6. DEFRA., (2011): "Sustainable clothing roadmap progress report 2011", (accessed 2011): www.defra.gov.uk/environment/economy/products/roadmaps/documents/clothingactionplan110317.pdf.

7. Walter, L., Kartsounis, G., Carosio, S., (2009): "Transforming clothing production into a demanddriven, knowledge-based, high-tech Industry", Springer, London.

8. Elasser, V. H., (2005): "Textiles: Concepts and principles", Fairchild, US.

9. Prasad, S. and Sounderpandian, J., (2003): "Factors influencing global supply chain efficiency: implications for information systems", Supply Chain Management, Vol.8, No.3, pp.241-250.

10.Barnes, L. and Lea-Greenwood, G., (2006): "Fast fashioning the supply chain: shaping the research agenda", Journal of Fashion Marketing and Management, Vol.10, No.3, pp.259-271.

11. Burns, D. L. and Bryant, N. O., (2007): "The business of fashion: Designing, manufacturing, and marketing, Fairchild Publications, New York.

12. Rodriguez, A., (2001): "Are you lean in product development?" Apparel Sourcing (accessed 2011): http://themagazineapparelsourcing.com/magazine/are-you-lean-in-product-development/.

13. Friedman, T., (2005): "The world is flat", Farrar, Straus and Giroux, US.

14. Barnes, L. and Lea-Greenwood, G., (2010): "Fast fashion in the retail store environment", International Journal of retail distribution Management, Vol.38, No.10, pp.760-772.

15. Sull, D. and Turconi, S., (2008),:."Fast fashion lessons”, Business Strategy Review, Vol.19, No.2, pp.4-11.

16. Hayes, S.G. and Jones, N., (2006): "Fast fashion: a financial snapshot", Journal of Fashion Marketing and Management, Vol.10, No.3, pp.282-300.

17. Sheridan, M., Moore, C., Nobbs, C., (2006): "Fast fashion requires fast marketing", Journal of Fashion Marketing and Management, Vol.10, No.3, pp.301-15.

18. Parker, L. and Dickson M. A., (2009): "Sustainable fashion", Look Behind the Label, UK.

19. Goldstein, Y., (2009): "Virtual prototyping: from concept to 3D design and prototyping in hours, in Walter, L. et al., Transforming clothing production into a demand-driven, knowledge-based, hightech Industry", Springer, London.

20. Stylios, G.K., (2005): "New measurement technologies for textiles and clothing", International Journal of Clothing Science and Technology, Vol.17, No.3/4, pp.135-149.

21. Luible, C. and Magnenat-Thalmann, N., (2007): "Suitability of standard fabric characterisation experiments for the use in virtual simulations", Proceedings of Autex 2007, Tampere, Finland.

22. Xu, B., Huang, Y., Yu, W., Chen, T., (2002): "Body scanning and modelling for custom fit garments", Journal of Textile and Apparel, Technology and Management, Vol. 2, No.2, pp.1-11.

23. Hardaker, C. H. M. and Fozzard, G. J. W., (1998): "Towards the virtual garment", International Journal of Clothing Science and Technology, Vol.10, No.2, pp.114-127.

24. Protopsaltou, D., Luible, M.A., Magnenat-Thalmann, N., (2002): "A body and garment creation method for an internet based fitting room", Proceedings of Computer Graphics International, Springer, pp.105-122.

25. Volino, P. and Magnenat-Thalmann, N., (2005): "Accurate garment prototyping and simulation", Computer-aided Design and Applications, Vol.2, No.5, pp.645-654.

26. Fang, J. J., (2003): "3D collar design creation", International Journal of Clothing Science and Technology, Vol.15, No.2, pp.88-106.

27. Sul, I. H. and Kang, T. J., (2006): "Interactive garment pattern design using virtual scissoring method", International Journal of Clothing Science and Technology, Vol.18, No.1, pp.31-42.

28. D'Apuzzo, N. (2011): http://www.fibre2fashion.com/industry-article/technology-industry-article/3dbody-scanning-technology (accessed on 15/08/11). 
29. Apeagyei, P.R,, Otieno, R. \& Tyler, D., (2007): "Ethical Issues and Methodological Considerations in Researching Body Cathexis for Fashion Products", Journal of Fashion Marketing and Management, Vol.11, No.3, pp.332-348.

30. Otieno, R.B., Harrow, C., \& Lea-Greenwood, G., (2005): "The Unhappy Shopper, A retail Experience: Exploring Fashion, Fit and Affordability", International Journal of Retail and Distribution Management, Vol.33, No.4, pp.298-309.

31. Fan, W.J. \& Hunter, L., (2004): "Clothing Appearance and Fit: Science and Technology", Woodland Publishing Ltd., Cambridge.

32. Anderson-Connell, L.J., Ulrich, P.V., (2002): "A Consumer-driven model for Mass Customization in the Apparel Market", Journal of Fashion Marketing and Management, Vol.6, No.3, pp.240-58.

33. Apeagyei, P.R., (2008): "Significance of Body Image among Female UK Fashion Consumers: the cult of Size Zero, the Skinny Trend", Journal of Fashion Design, Technology and Education, Vol.1, No.1, pp.3-11.

34. Workman, J.E. \& Lentz, E.S., (2000): "Measurement Specification for Manufacturers for Prototype Bodices", Clothing and Textiles Research Journal, Vol.18, No.4, pp.251-256.

35. Tamburrino, N. (1992a): “Apparel Sizing Issues: Part 1", Bobbin, Vol.33, No.8, pp.44-47.

36. Tamburrino, N. (1992b): "Apparel Sizing Issues: Part 2", Bobbin, Vol.33, No.9, pp.52-60.

37. Tamburrino, N. (1992c): "Sized to Sell", Bobbin, Vol.33, No.10, pp.68-74.

38. Shape Analysis, (2009): http://www.shapeanalysis.com (accessed on 25/09/09).

39. Simmons, K.P. \& Istook, C.L., (2003): "Body Measurement Techniques: Comparing 3D BodyScanning and Anthropometric Methods for Apparel Applications", Journal of Fashion Marketing and Management, Vol.7, No.3, pp.306-332.

40. Simmons, K.P. \& Istook, C.L., (2001): "Body Measurement Techniques: a Comparison of 3D Body Scanning and Physical Anthropometric Methods". In Proceedings of the KSCT/ITAA Joint World Conference, Seoul, South Korea, ITAA Publications.

41. Ashdown, S.P., Loker, S., Schoenfelder, K. \& Lyman-Clarke, L., (2004): "Using 3D Scans for Fit Analysis", Journal of Textile and Apparel, Technology and Management, Vol.4, No.1, p12.

42. Cyberware, (2010): http://www.cyberware.com (accessed on 20/10/10).

43. [TC] ${ }^{2}$, [online], http://www.tc2.com (accessed on 20/10/10).

44. Wicks and Wilson, (2010): http://www.wwl.co.uk (accessed on 20/10/10).

45. Telmat Industrie, (2010): http://www.symcad.com (accessed on 20/10/10).

46. Istook, C.L. \& Hwang, S., (2001): "3D Body Scanning Systems with Application to the Apparel Industry", Journal of Fashion Marketing and Management, Vol.5, No.2, pp.120-132.

47. Gerber (2011) "Vstitcher by BROWZWEAR for Apparel/Fashion" (accessed 2011) www.gerbertechnology.com/downloads/pdf/AccuMark Vstitcher Apparel E.pdf.

48. Tubbs, M. C. and Daniels, P. N., (1991): "Textile terms and definitions", The Textile Institute, UK.

49. Minazio, P.G., (1995): "FAST - Fabric assurance by simple testing", International Journal of Clothing Science and Technology, Vol.7, No.2/3, pp.43-48.

50. Kawabata, S., (1980): "The standardization and analysis of hand evaluation", The Textile Machinery Society of Japan, Osaka.

51. Lindberg, J., Behre, B., Dahlberg, B., (1961): "Mechanical properties of textile fabrics: Shearing and buckling of various commercial fabrics", Textile Research Journal, Vol.31 No.2, pp. 99-122.

52. Peirce, F.T., (1930): "The handle of cloth as a measurable quantity", Journal of the Textile Institute, Vol.21, No.9, pp.377-416.

53. Boos A. D. and Tester, D., (1994): "SiroFAST: A System for fabric objective measurement and its application in fabric and garment manufacture", Report no. WT92.02 CSIRO.

54. Ly, N. G., Tester, D.H., Buckenham, P., Roczniok, A. F., Adriaansen, A. L., Scaysbook, F., De Jong, S., (1991): "Simple instruments for quality control by finishers and tailors", Textile Research Journal, Vol.61, No.7, pp.402-407.

55. McLoughlin, J., (2008): "Chapter 13: Automated fabric inspection" in Fairhurst, C., Advances in apparel production, Woodhead, London.

56. Bishop, D. P., (1996): " Fabric Sensory and Mechanical Properties", Textile Progress, Vol.26, No.3, pp.1-64.

57. Volino, P. and Magnenat-Thalmann, N., (2000): "Virtual clothing", Springer, London.

58. Wacker, M., Keckeisen, M., Kimmerle, S., Straber, W., (2005): "Simulation and visualisation of virtual textiles for virtual try-on", RJTA, Vol.9, No.1, pp.37-47.

59. Browzwear (2009): "What's New Vstyler, VViewer Version 4.4", Browzwear.

60. Endosomwan, J.A., (1996): "Organisational Transformation and Process Re-engineering", St. Lucie Press, Florida, 1996. 